\title{
1 High Mortality Rate Due to Novel Coronavirus and Deficient \\ 2 Magnesium Intake by Countries
}

3

4 Masahiro Teduka $^{1}$ and Md. Abdul Masum²,3

5

$6 \quad{ }^{1}$ ICE2.0 LLC, Sapporo, Japan

$7 \quad{ }^{2}$ Laboratory of Anatomy, Department of Basic Veterinary Sciences, Faculty of 8 Veterinary Medicine, Hokkaido University, Sapporo, Japan.

$9 \quad{ }^{3}$ Department of Anatomy, Histology and Physiology, Faculty of Animal Science and 10 Veterinary Medicine, Sher-e-Bangla Agricultural University, Dhaka, Bangladesh

Abstract

The mortality rate due to COVID-19 is much lower in Asia and Africa than in developed countries in Europe and the United States (West), and this has become an issue that is attracting a great deal of attention. On the other hand, it has recently become clear that the mineral Magnesium $(\mathrm{Mg})$ is significantly related to human immune function, and most people in the West have insufficient Mg intake. Furthermore, it has become clear that the conventional standards for $\mathrm{Mg}$ intake are inadequate to indicate insufficient $\mathrm{Mg}$ intake. This report shows that regional and national differences in $\mathrm{Mg}$ intake are largely responsible for the differences in deaths per infected people (D/IP) caused by COVID-19: the West and Indonesia are considered to have low dietary Mg intakes, resulting in high D/IP; and India $\cdot$ Bangladesh and Africa are the opposite.

Keyword: COVID-19, diet, Immunity, Magnesium, Mortality Rate 


\section{Background}

Novel coronavirus (COVID-19) has become a pandemic and the world is in unprecedented crisis. In this situation, WHO has reported that the mortality rate due to COVID-19 is much lower in Asia and Africa than in Western developed countries (West)

(Table 1), and this has become an issue that is attracting a great deal of attention. At present, various studies such as genetic and previous viral infection have been proposed to explain this (Zeberg et al., 2020; Kamikubo et al., 2020). However, these studies have limited numbers of countries/regions to compare mortality rates. There are also inconsistencies in the mortality rates by countries/regions. elucidation of the function of intracellular $\mathrm{Mg}$ in immune cells has been progressing. As results, it has been reported which $\mathrm{Mg}$ is significantly related to the immune function, and which most people in the West have inadequate dietary intake of $\mathrm{Mg}$ for the immune function (Chaigne-Delalande et al., 2013; de Baaij et al., 2015; Kanellopoulou et al., 2019). Further, Mg has a strong homeostasis, which is constant in serum, and most mild and moderate diseases due to its deficiency are asymptomatic (subclinical $\mathrm{Mg}$ deficiency) (Costello et al., 2016). Thus, the asymptomatic Mg deficiency cannot be judged by conventional serum concentration or dietary intake standard (Costello and Nielsen 2017). 
We consider the comparative indicator of COVID-19 mortality rate and its influencing factors as follows.

Comparative indicators of mortality rates by countries are deaths per population or deaths per infected people (D/IP). The current status of COVID-19 infection by countries is a mixture of starting points of infection, and of periods of expansion or contraction. Therefore, the number of deaths per population is not an appropriate indicator for comparing mortality rates based on differences in country characteristics. In this report, we use D/IP as a comparative indicator of mortality rates by countries.

In the present study, we consider that factors affecting the number of deaths due to COVID-19 can be divided into following three categories: 1) pre-infection behavior and habits of infected peoples; 2) immune strength (immunity) of infected peoples; and 3) treatment environment of infected peoples. Among these factors, the "pre-infection behavior and habits of infected peoples" factors include 3-density (crowded, close and sealed), handshaking, hugging, and living with shoes in the house, which are not common in Japan. The "immunity" factors include diets, which are habituation of nutrients-containing foods for immune cells, and age, which have influence on the intake and absorption rate of the nutrients, reducing immunity with aging (Sakamoto et al., 1986). Finally, the "treatment environment" factors are as medical facilities and systems for treatment of infected peoples.

In addition, D/IP in the above comparative indicator is the percentage of deaths that occur after infection. The cause of the deaths is therefore related to the "immunity" factors and the "treatment environment" factors excluding "pre-infection behavior and habits of infected peoples" factors in the above influencing factors.

Furthermore, we consider outdoor temperature and humidity. At the time of writing this report, around October 2020, the number of infected people in the west began to 
increase again (the third wave). The assessment that the outdoor temperature and humidity are the cause of this third wave is widely believed. The rationales are that 1) the activation time of COVID-19 is longer at lower temperatures, and the existing time of COVID19-containing droplets in the air increases with lower humidity: these factors increase the probability of infection (Mohammad et al., 2020; Mecenas et al., 2020). Also, 2) a decrease in ambient temperature and humidity has a negative impact on immunity and the medical environment. However, in this our research, it seems that the influences of the ambient temperature and humidity in different regions/countries can be neglected for the following reasons: 1) The temperature and humidity in D/IP are not that of the outside air, but rather the normal temperature and humidity controlled by the air conditioning of the treatment facility. 2) The West with large D/IPs (3.2), where are lower outdoor temperature and humidity, tend to have air conditioning in their treatment facilities. 3) Indonesia (3.2), where has a large D/IP, has a high outdoor air temperature.

\section{Foodstuffs and D/IP on regions/countries}

Foodstuffs for daily diet vary greatly among regions/countries in the world. Therefore, there are regions/countries that eat $\mathrm{Mg}$-rich foods and vice versa. Notably, grains, which are staple foods, are removed brans by milling and polishing in many countries (Aune et al., 2016). The brans contain a very large amount of $\mathrm{Mg}$ compare to other food stuffs (Slavin et al., 2001; Zong et al., 2016; Aune et al., 2016) (Table 2: Standard table 2020; Netravati et al., 2018; Bogard et al., 2016; US department 2019).

\subsection{Foodstuffs}

\section{Europe and US}

Western diet has the following characteristics in relation to $\mathrm{Mg}$ intake (de Baaij et al., 2015; Kanellopoulou et al., 2019). 
- Meat and/or bread are a staple food with low Mg (Table 2).

- Western diet contains refined grains and many processed food. It has been estimated that about $80-90 \%$ of $\mathrm{Mg}$ is lost during food processing

Asia

In Asia, rice is the staple food of most countries. However, rice is mostly eaten in the same country where it is produced with diverse differences including rice types (indica, japonica and javanica), parboiling (3.2) or non-parboiling and milling degrees (Muthayya et al., 2014).

109 The important thing is that rice is covered with bran, which contains a large amount of 110 the mineral $\mathrm{Mg}$ (Table 2).

\section{Africa}

112 In Africa, maize, sorghum and millet are staple food, which contain a large amount 113 of $\mathrm{Mg}$ (Table 2). Moreover, pulses, which are rich in $\mathrm{Mg}$, are also eaten a lot (Oniang'o 114 et al., 2003; Leff et al., 2004). Furthermore, most Africans eat whole grains (e.g., sorghum, millet and teff) including bran without milling (Oniang'o et al., 2003). The bran of the grains contains a large amount of $\mathrm{Mg}$ (Aune et al., 2016).

\subsection{D/IP and mineral Mg}

\section{The West}

The West have higher D/IPs in general (Table 1). The treatment environments in the west are better than in the developing countries. However, the average age of the that this is due to the following unusual treatment environment for COVID-19 on population is high. These indicate that age and/or diet can be a candidate for the cause of the high West D/IP.

Germany is the only country in the west with a low D/IP (Table 1). We consider German (Okina et al., 2020): 1) a large number of physicians per population; 2) a very 
large number of intensive care units (ICU) per population; 3) a very large number of intensivist per population; 4) the centralization of ICUs to large hospitals; 5) the information such as ICU availability are online, allowing for efficient decentralization of critically patients and 6) all infected patients are admitted to the hospitals Asia

Indonesia's D/IP is the largest in Asia and is more than double that of India and Bangladesh $(\mathrm{I} \cdot \mathrm{B})$ (Table 1). Rice is the staple food in these countries. What is unique about rice in Indonesia compared to other countries is that the political changes during 1965-1968 (transition from Sukarno to Soeharto political power followed by deregulation, open economy and Indonesianism) led to the rapid spread of high performance rice milling and polishing machines to every corner of the country (Koga, 1989). In addition, Indonesia's people prefer milled and polished white rice, which remove bran layer on the brown rice surface; and higher whiteness and luster rice is traded at higher price (Koga, 1989). For this reason, the rice that is the staple food of the Indonesia's people have been removed most of the bran layer, being low $\mathrm{Mg}$ content.

On the other hand, unlike other Asian countries, $\mathrm{I} \cdot \mathrm{B}$ has a large number of people who eat parboiled rice as their staple food (Arai, 1980; Ando, 1987). Parboiling is a processing method that typically involves three steps of soaking, boiling and drying raw rice before threshing. The parboiled rice has the following advantages (Arai, 1980): 1) The rice is hardened and therefore is less broken rice during threshing and milling: the yield is very high. 2) Nutrients such as vitamins and proteins in bran are transferred in white kernels. 3) Good storability. On the other hand, the disadvantages of the rice are the hardening, coloring and special smell. As mentioned above, the parboiled rice has a higher yield. For this reason, in $\mathrm{I} \cdot \mathrm{B}$, there are many areas where the raw rice is parboiled and then the parboiled rice is processed using a Huller machine with a simple operation 
and structure, which threshing and milling are done simultaneously (Muthayya et al., 2014; Arai, 1980; Bodie et al., 2019). The use of above the parboil-processed rice and the Huller machine results in a large bran (high $\mathrm{Mg}$ content) remaining in the produced rice (Arai, 1980; Kennedy et al., 2002) (Even if the Huller machine is not used and the threshing and milling process are separated, milling processed white rice implies only 8-10 percent bran removal, and further bran removal requires polishing process: Kennedy et al., 2002). Furthermore, in Bangladesh, the amount of rice eaten is very large (Kennedy et al., 2002). Also, in India, pulses, millet, sorghum and maize with a lot of $\mathrm{Mg}$ are eaten in large quantities (Leff et al., 2004). In addition, $\mathrm{I} \cdot \mathrm{B}$ people prefer the smell and coloring of the parboiled rice (Arai, 1980; Lyon et al., 1999).

Indonesia's D/IP is more than double that of $\mathrm{I} \cdot \mathrm{B}$. Indonesia and $\mathrm{I} \cdot \mathrm{B}$ are not much difference in the average ages in immunity factors (Table 1) and seem to be not much difference the treatment environment factors. Therefore, the differences in D/IP can be attributed to the difference in $\mathrm{Mg}$ intake by diet.

\section{Africa}

The D/IP in Africa is smaller than in the West (Table 1). The treatment environment in Africa is poor compare to the West. However, the D/IP is small. Therefore, the treatment environment as causes for the smaller D/IP in Africa compared to the West is excluded. On the other hand, the average age in Africa is young (Table 1). These lead to age and diet of immunity as the possible causes of smaller D/IP in Africa.

\section{Conclusion}

It seems that regional and national differences in $\mathrm{Mg}$ intake are largely responsible for the differences in D/IP caused by COVID-19. The developments and inoculations of vaccines for COVID-19 are eagerly awaited by people all over the world. However, 
176 behind the scenes, the durations of the vaccine effects and mutant viruses are regarded

177 as hurdle. The awareness of enough Mg intake for COVID-19 may give people more 178 hope than the inoculation of the vaccines. 
Table 1 Infection status on countries by COVID-19

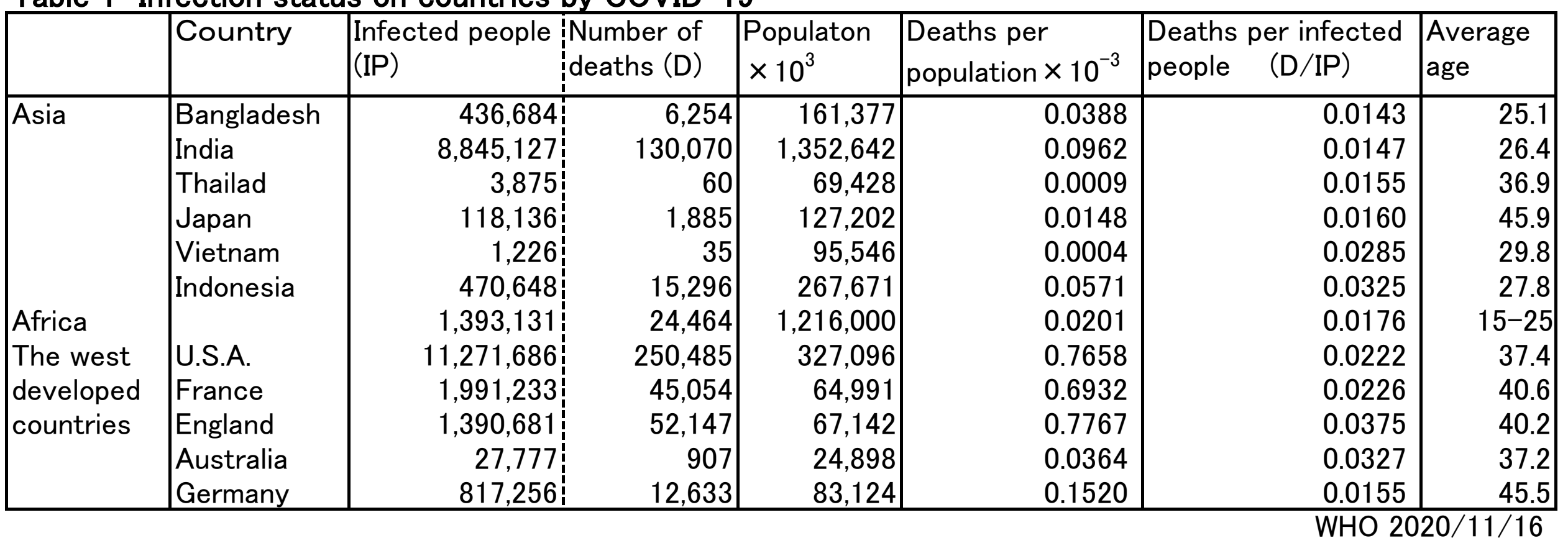


Table 2 Mg contents of foods $\left.{ }^{2} 1\right)$ $\mathrm{mg} / 100 \mathrm{~g}$

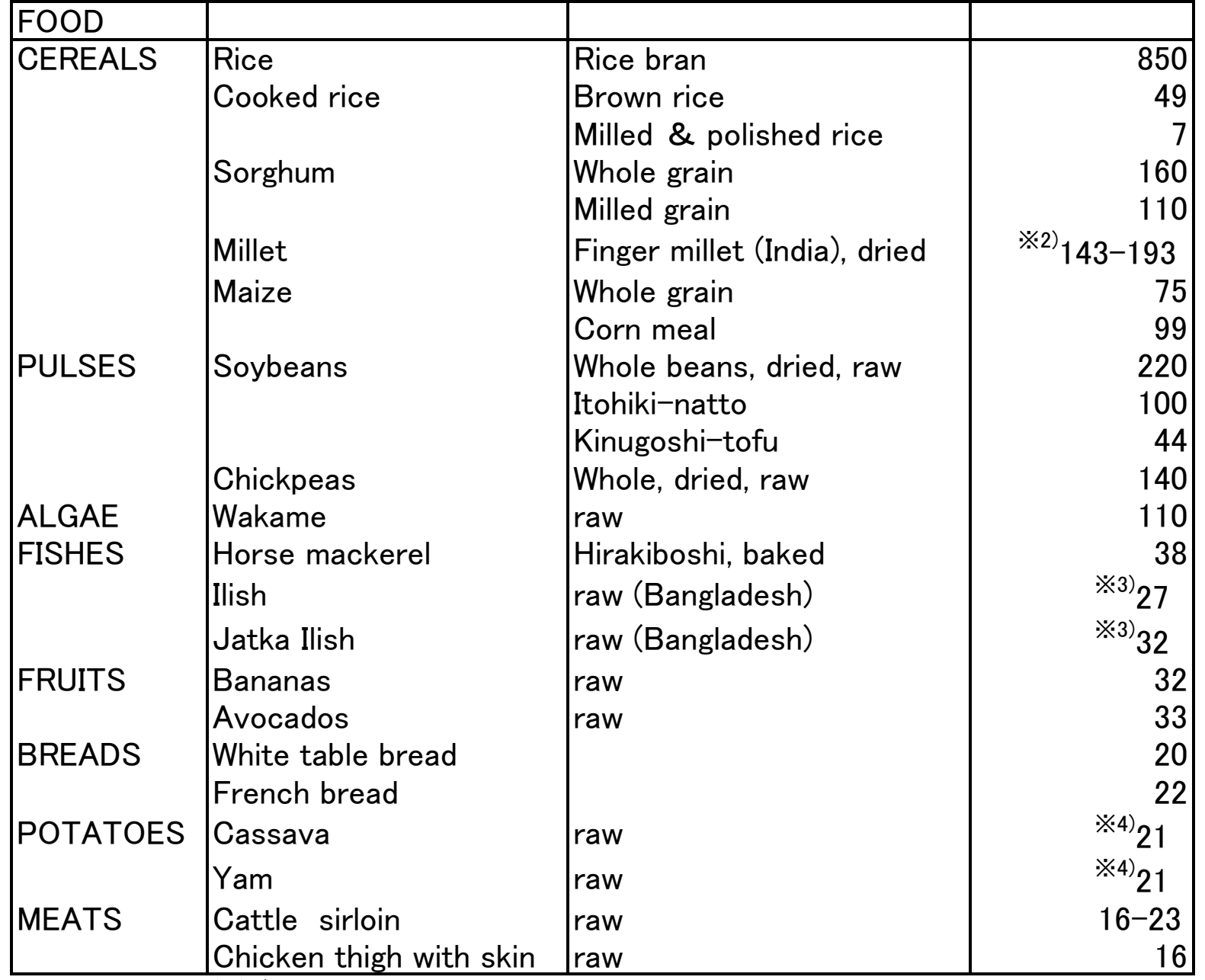

$※ 1$ ) Ministry of Education, Culture, Sports, Science and Technology, 2020

$※ 2)$ Netravati, 2018

※3) Bogard, 2015

※4) U.S. DEPARTMENT OF AGRICULTURE, 2019 


\section{$1 \quad$ References}

2 Ando, K. (1987) Rice Cultivation in the Low-lying Areas of the Bengal Delta - A Note on Aus and Broadcast Aman Cultivation and Parboiled Rice in the Eastern Region of Bangladesh. Southeast Asian Studies; 25(1):125-139.

Arai, K. (1980) Processing Parboiled Rice. Jpn J Trop Agr , 24(2):6268.

Aune, D., N. N. Keum, E. Giovannucci, L. T. Fadnes, P. Boffetta, D. C. Greenwood, S. Tonstad, L. J. Vatten, E. Riboli and T. Norat (2016) Whole grain consumption and risk of cardiovascular disease, cancer, and all cause and cause specific mortality: systematic review and dose-response meta-analysis of prospective studies. $B M J, 353$

Bodie, A. R., A. C. Micciche, G. G. Atungulu, M. J. Rothrock Jr and S. C. Ricke (2019) Current trends of rice milling byproducts for agricultural applications and alternative food production systems. Frontiers in Sustainable Food Systems 3, 47

Bogard, J. R., S. H. Thilsted, G. C. Marks, M. A. Wahab, M. A. R. Hossain, J. Jakobsen and J. Stangoulis (2015) Nutrient composition of important fish species in Bangladesh and potential contribution to recommended nutrient intakes. Journal of Food Composition and Analysis 42, 120-133

Chaigne-Delalande, B., F. Y. Li, G. M. O'Connor, M. J. Lukacs, P. Jiang, I. Zheng, A. Shatzer, M. Biancalana, S. Pittaluga, H. F. Matthews, T. J. Jancel, J. J. Bleesing, R. A. Marsh, T. W. Kuijpers, K. E. Nichols, C. L. Ucas, S. Nagpal, H. Mehmet, H. C. Su, J. I. Cohen, G. Uzel and M. J. Lenardo (2013) Mg2+ regulates cytotoxic functions of NK and CD8 T cells in chronic EBV infection through NKG2D. Science, Jul 12;341(6142):186-91.

Costello, R. B., R. J. Elin, A. Rosanoff, T. C. Wallace, F. Guerrero-Romero, A. Hruby, P. L. Lutsey, F. H. Nielsen, M. Rodriguez-Moran, Y. Song and L. V. Van Horn (2016) Perspective. The Case for an Evidence-Based Reference Interval for Serum Magnesium: The Time Has Come. Adv Nutr, Nov 15;7(6):977-993. 
Costello., R. B. and F. Nielsen (2017) Interpreting magnesium status to enhance clinical care: key indicators. Curr Opin Clin Nutr Metab Care, Nov;20(6):504-511.

de Baaij, J. H., J. G. Hoenderop and R. J. Bindels. (2015) Magnesium in man: implications for health and disease. Physiol Rev. , Jan; 95(1), 1-46.

Kamikubo, Y. and A. Takahashi (2020) Paradoxical dynamics of SARS-CoV-2 by herd immunity and antibody-dependent enhancement. Cambridge Open Engage, 1-39

Kanellopoulou, C., A. B. George, E. Masutani, J. I. Cannons, J. C. Ravell et al. (2019) $\mathrm{Mg}^{2+}$ regulation of kinase signaling and immune function. $J$ Exp Med. , Aug 5, 216(8), 1828-1842. .

Kennedy, G., B. Burlingame and N. Nguyen (2002) Nutrient impact assessment of rice in major rice-consuming countries. International Rice Commission Newsletter (FAO), 33-41

Koga, Y. (1989) Development of Rice Postharvest Processing Technology in Asian Countries and the Socio-economic Factors (Part 1). J Jpn Soc Agr Mach, 51,127-135.

Leff, B., N. Ramankutty and J. A. Foley (2004) Geographic distribution of major crops across the world. Global biogeochemical cycles 18, GB1009, 1-27

Lyon, B. G., E. T. Champagne, B. T. Vinyard et al. (1999) Effects of degree of milling, drying condition, and final moisture content on sensory texture of cooked rice.Cereal chemistry $76(1), 56-62$

Mecenas, P., R. T. R. M. Bastos, A. C. R. Vallinoto and D. Normando (2020) Effects of temperature and humidity on the spread of COVID-19: A systematic review. PLoS one 15 (9), e0238339

Mohammad, M. S., H. Parham, V. Augustin, S. Shervin, M. Fernando and A. Anthony (2020) Temperature, humidity, and latitude analysis to estimate potential spread and seasonality of coronavirus disease 2019 (COVID-19), JAMA network open 3 (6), e2011834-e2011834

Muthayya, S., J. D. Sugimoto, S. Montgomery and G. F. Maberly (2014) An overview of global 
rice production, supply, trade, and consumption. Annals of the new york Academy of Sciences $1324(1), 7-14$

Netravati, H., K. Geetha, S. R. Vikram, Y. A. N. Reddy, N. Joshi and H. B. Shivaleela (2018) Minerals content in finger millet [Eleusine coracana (L.) Gaertn.]: A future grain for nutritional security. International Journal of Current Microbiology and Applied Sciences, $3448-3455$

Okina, Y., O. Renn and A. Lohse (2020) What Can We Learn From Germany's Response to COVID-19? - Medical Preparedness / Flexible Responses / Management of Public Funds-. NIRA OPINION PAPER No.54, October, 1-18

Oniang'o, R. K., J. M. Mutuku and S. J. Malaba (2003) Contemporary African food habits and their nutritional and health implications. Asia Pac J Clin Nutr,12(3), 331-6.

Sakamoto, M., S. Kobayashi, S. Sishii, T. Mori and T. Ooyama (1986) Some Nutritional Parameters and Immunocompetence in Elderly People. J Jpn Soc Nutr. Food Sci, 39, 1-8

Slavin, J. L, D. Jacobs, L. Marquart and K. Wiemer (2001) The role of whole grains in disease prevention. J Am Diet Assoc, 101:780-5. 10.1016/S0002-8223(01)00194-8

Standard Tables of Food Composition in Japan 2020 (8th edition) (2020) Ministry of Education, Culture, Sports, Science and Technology, Japan.

U.S. DEPARTMENT OF AGRICULTURE (2019) Agricultural Research Service, FoodData Central, https://fdc.nal.usda.gov/ndb/search/list

Zeberg, H., and S. Pääbo (2020) The major genetic risk factor for severe COVID-19 is inherited from Neanderthals, Nature, 587 (7835), 610-612

Zong, G., A. Gao, F. B. Hu and Q. Sun (2016) Whole grain intake and mortality from all causes, cardiovascular disease, and cancer: a meta-analysis of prospective cohort studies. Circulation 133 (24), 2370-2380 